\title{
IMPORTANCIA DE LA VOZ Y LA PALABRA EN EL TEATRO REPRESENTADO
}

\author{
Orlando J. Genó
}

1

Hablar de la "importancia de la voz y la palabra en el teatro representado" tiene para mi un doble valor afectivo: por un lado, porque todo lo relacionado con el lenguaje humano ha sido desde siempre una de mis más caras inquietudes y, por el otro, porque la actuación teatral sigue siendo una de mis vocaciones frustradas. Sin embargo, en mi ya larga vida he tratado de conciliar ambos sentimientos: sea mediante algunas esporádicas experiencias escénicas o de teatro leído, sea a través de mi participación en coros, audiciones radio-televisivas o como disertante en actos culturales, pero, sobre todo, por obra y gracia de mi función docente: sabido es que un buen maestro debe saber desplegar frente a su auditorio toda una gama de habilidades histriónicas.

En principio, creemos necesario aclarar que, dada la naturaleza de este artículo, no vamos a exponer una teoría del lenguaje, sino apenas algunos aspectos lingüístico-expresivos que todavia preocupan a la gente de teatro. Eso sí, no dejaremos de insistir en que el lenguaje humano no sólo es el medio de comunicación más competitivo de que se vale el hombre, sino su mejor definición. El único rasgo pertinente que mejor lo diferencia de las demás criaturas.

Es cierto que a menudo se habla del lenguaje de los animales, incluso con nombres propios según la especie: la pantera y la onza himplan, el pato parpa, el cuervo y el grajo crascitan y croajan, el jabalí rebudia, el búho ayea, la grulla gruye, el perro hipa, gañe y regaña. Se habla del lenguaje de la danza: aquí, en Argentina, continúa el diálogo amoroso de los pañuelos en la zamba criolla; del lenguaje de las artes plásticas que nos susurran sus esfuminos o nos gritan sus atormentadas formas; del cautivante lenguaje de la música, inagotable caudal de sonidos, arpegios y melodías; del lenguaje de la ciencia más veneranda y de la tecnología más sofisticada que nos franquea el hermetismo de sus notaciones, claves y formulaciones algebraicas. Hasta se habla de las "voces de la naturaleza", algunas de ellas pintorescas, si no asombrosas: los ríos tararean, susurran y murmuran; el viento gime, zumba y ulula, el granizo tintinea, crepita y restalla.

No obstante, el lenguaje humano sigue siendo, entre todos los lenguajes, el más eficiente y completo, cuasi perfecto, incluso todavía perfectible. Y esto es así por tantísimas razones: sólo él es capaz de alcanzar altas cumbres de abstracción como arrastrarse en mil bajezas y ruindades. Sólo él puede, sincréticamente, combinar las mejores condiciones de las bellas artes: colores, perspectivas, acentos, relieves, dimensiones, tonos, estructuras, formas, armonías. Sólo él, con flagrante economía de fonos y grafias hábilmente combinados, puede manifestar infinitos contenidos mentales que responden a pautas socio-culturales y, a la vez, psico-individuales, que se valen de infinitas referencias y formas expresivas para lograr un 
eficaz intercambio comunicativo. En suma: hasta sólo el puede hablar de sí mismo, por sí mismo y consigo mismo.

Dada tal complejidad es que decidimos no insistir en los viejos dilemas que giran en torno del lenguaje humano, sobre todo porque mucho se ha discurrido acerca de ellos. Quiere decir, entonces, que no vamos a plantear aquí si el lenguaje es más importante que el pensamiento o si el uno es anterior o posterior al otro, o bien, como lo replantea Edward Sapir, 'si sería posible el pensamiento sin el habla o bien si el habla y el pensamiento no serian otra cosa que dos facetas de un mismo proceso psíquico". Como testimonio de este dilema aún sin respuesta definitiva recordemos que Platón concebía un Cosmos de las Ideas, esférico, supraceleste y eterno, que trascendía la miserable cobertura humana en la que había quedado prisionera el alma y, con ella, el lenguaje, mientras en la actualidad el poeta español Dámaso Alonso lo libera a tal punto de convertirlo en el hacedor omnisciente de las cosas terrenales cuando, impregnado en el subjetivismo del más neto corte berkelyano, afirma "yo hice el mundo en mi lengua castellana"2. Desde nuestro punto de vista sólo importa que, en última instancia la verdad es tal como la plantea don Ramón del Valle-Inclán: "El secreto de las conciencias sólo puede revelarse en el milagro musical de las palabras" $"$.

Tampoco vamos a discutir si las palabras valen más o menos que las acciones, que la voluntad o, si se quiere, que la intención de los hablantes. Desde la máxima aristotélica "res non verba" hasta la última pragmática o "teoría de la interacción lingüistica" mucho se ha lucubrado en favor de unas y en desmedro de las otras, olvidando la mayoría de las veces que el acto de hablar es, al fin de cuentas, un acto de voluntad mediante el cual "se hace algo" en el momento en que "se dice algo"; de allí que todo acto de habla sea un acto responsable de buena voluntad y compromiso. Porque todo acto de habla, aparte de revelar la carga cultural, ideológica y psíquica de los hablantes, conjunta la capacidad psicolingüistica de los individuos con el contexto histórico-social que los mueve a hablar, a interrelacionarse verbalmente y a comprometerse con la acuciante realidad que les toca vivir. Semejante compromiso obliga a los hombres a hacerse responsables de lo que dicen y de cómo, cuándo, dónde y ante quienes lo dicen. Al respecto, Michel Pêcheux formuló las formaciones imaginarias que supone todo proceso discursivo:

"¿Quién soy yo para hablarle asi?

¿Quién es él para que yo le hable asi"

¿Quién soy yo para que él me hable asi"

¿Quién es él para que me hable asi?";

\footnotetext{
${ }^{1}$ Cfr. E. SAPIR, El lenguaje. Introducción al estudio del habla, México, Fondo de Cultura Económica, 1954, p. 20.

${ }^{2}$ Cfr. D. ALONSO, Tres sonetos sobre la lengua castellana, Madrid, Gredos, p. 8. Tales sonetos se incluyen en las "Palabras pronunciadas por Dámaso Alonso, en el homenaje que le dedicó el Gremio de Libreros de Madrid, el 30 de marzo de $1958^{\prime \prime}$.

3 Vid. R. DEL VALLE-INCLÁN, "El milagro musical", en La lámpara maravillosa, OBRAS COMPLETAS, Madrid, Ed. Plenitud, 1954, Tomo II, p. 571.
} 
y, tras ellas, puntualizó la pregunta implícita cuya respuesta subyace debajo de la formación imaginaria correspondiente:

“De qué le hablo asi?

¿De qué me habla asi?"

Dicho de otro modo, todo acto de habla es en esencia un acto ético, moral que, como tal, exige sinceridad, obligación, respeto, prudencia y ¡Dios sabe cuántas condiciones más!, de manera tal que no alcance a constituir un acto desafortunado, falaz o artero. Por eso, continuamente nos viene a la memoria esta sabia reflexión de Ortega y Gasset: "Se ha abusado de la palabra y por eso ha caido en desprestigio. (...) Desde hace casi dos siglos se ha creido que hablar era hablar urbi et orbi, es decir, a todo el mundo y a nadie (...). Esta costumbre de hablar a la Humanidad, que es la forma más sublime y, por lo tanto más despreciable de la demagogia, fue adoptada hacia 1750 por intelectuales descarriados, ignorantes de sus propios limites y que siendo, por su oficio, los hombres del decir, del logos han usado de él sin respeto ni preocupaciones, sin darse cuenta de que la palabra es un sacramento de muy delicada administración",

De igual modo, no vamos a cuestionar aquí si, en el intercambio comunicativo de nuestra vida de relación cotidiana, la expresión verbal ejerce (o no) su hegemonía sobre la expresión psicosomática (dicción, entonación adecuada al carácter del texto, gestos, ademanes, movimientos corporales, desplazamientos) y demás componentes del contexto situacional, cuestión sumamente controvertida sobre todo por aquéllos que usan la voz como herramienta de trabajo, por quienes se desempeñan habitualmente ante auditorios masivos y exigentes: catedráticos universitarios y docentes en general, animadores de radio, televisión y de diversos actos públicos, oradores políticos, militares y religiosos, actores teatrales, radiales y televisivos, camaristas judiciales y parlamentarios, funcionarios oficiales y privados, y toda suerte de comunicadores sociales.

Ahora bien, lo que sí vamos a sustentar aquí es nuestra opinión -obviamente opinable, por supuesto- de que mientras haya un texto para ser representado o simplemente manifestado en la forma que fuere, sea breve o extenso, la voz y la palabra cobran de inmediato y proporcionalmente, la misma importancia de los otros componentes de la situación comunicativa.

Llegado a este punto, es tiempo de preguntarse si, en la representación escénica, la expresión lingüística (vocal) debe primar sobre la expresión corporal o viceversa; uno de los asuntos más discutidos en los círculos teatrales contemporáneos. Sabido es que el teatro tradicional hasta el siglo décimonono privilegiaba los textos, muchos de ellos verdaderas obras maestras de la literatura del mundo occidental. En cambio, a partir de fines de dicho siglo, tal

\footnotetext{
${ }^{4}$ Vid. M. PÊCHEUX, Hacia el análisis automático del discurso, Madrid, Gredos, 1978, pp. 49-50.

5 Vid. J. ORTEGA Y GASSET, "Prólogo para franceses", en La rebelión de las masas, Madrid, Revista de Occidente, 1961,p. 4.
} 
privilegio cambiaría, sobremanera con el surgimiento del teatro simbolista que nucleaba diversas tendencias que compartían unos mismos criterios sobre lo que debía ser el mundo propio del teatro: mundo alejado de la realidad y más cercano a lo irreal, mágico, maravilloso, para lo cual el lenguaje de la escena debía sustituir a menudo la verbosidad, aunque artística, de la dramaturgia clásica. Criterio que, sentido a ultranza, impulsó a algunos movimientos teatrales a renegar del maquillaje, vestuario, decorados, hasta del escenario mismo, a la vez que incorporaban como factores importantes del nuevo teatro la luz, la música y unos pocos, imprescindibles, elementos decorativos; todos ellos esquemáticos, sugerentes y subordinados al juego escénico. Testimonios conocidos al respecto son los que brindaron la escuela francesa de Jacques Copeau y la escuela rusa de Stanislavsky: la primera exageró el deseo de despersonalizar a los actores, razón por la cual, tras suprimir todo lo accesorio, les infligió una severísima preparación gimnástica, casi acrobática, y los lanzó a actuar entre y con el público; muestra cabal de la importancia que se le daba a la expresión corporal, al esquematismo decorativo y a la comunión entre el público y los actores; y la segunda promovió el análisis psicológico de los personajes y fundó el método de la formación psicotécnica de los actores, destinada a vivir en escena la llamada soledad pública y la intercomunicación psíquica entre los distintos actores en escena; todo con la menor cantidad de palabras, las imprescindibles. Es claro que, por la misma época y como contrapartida de tal desvalorización de la palabra, el Teatro Irlandés, fundado en 1899, reivindicó la belleza de la voz humana al depurar el arte declamativo mientras los actores permanecían de espaldas al público en absoluta inmovilidad ${ }^{6}$.

Entretanto, recrudecía la pugna entre el tradicional "teatro de la palabra" y el novísimo "teatro de la acción", aunque los mejores resultados favorecían más al segundo que al primero; de allí, el resurgimiento del secular arte de la mímica que pulió sus aristas expresivas y logró efectos insospechados en el sortilegio inigualable de Marcel Marceau, y, conjuntamente, la aparición de infinidad de experiencias plástico-gimnásticas, de juegos escénicos combinados con otras modalidades técnico-artísticas: teleteatro, cineteatro (o teatro filmado), teatro-danza, aparte de las mil variantes del llamado varieté o music-hall, incluidos los café-concert, los unipersonales, las revistas musicales, los recitales de música popular, etc.?

Sin embargo, la controversia "expresión corporal" vs. "expresión lingüistica" todavía continúa, y continuará por mucho tiempo, debido a la naturaleza propia del teatro y ésta, a sus raíces más intimas. Para comenzar a entenderlo, podemos partir de ciertas premisas:

1) desde sus orígenes en Grecia y Roma, el teatro ha sido en nuestra cultura el primero en conjuntar la comunicación lingüística-auditva con la comunicación visual;

2) la ya larga historia del teatro nos permite recurrir a él como el mayor confesionario de la historia, tal como lo definiera Ortega y Gasset.

\footnotetext{
${ }^{6}$ Cfr. A. CIRICI PELLICER, El teatro, en Enciclopedia Labor, Barcelona-Madrid 1959, T. VIII, pp. 618-620.

7 Nótese que no incluimos en este lugar los géneros mayores clásicos estrechamente ligados con la escenificación teatral: ópera, opereta, comedia musical, zarzuela, porque pertenecen al espectáculo teatral tradicional.
} 
Es evidente que ambas premisas están desentrañando su doble valor de comunicación/confesión por un lado, y de audición/visión por el otro; y, simultáneamente, restituyéndole a la palabra la relevancia que siempre tuvo en la naturaleza misma del teatro. Es decir, cuando hablamos de "lenguaje teatral", no podemos desconocer que, en cuanto dispone de lenguaje humano, éste combina elementos linguísticos (sonidos, palabras, frases, oraciones, secuencias sentenciales, parlamentos enteros, de múltiple valor fonológico, morfológico, sintáctico, semántico, pragmático, estilístico), con elementos paralingüísticos (acentos, flexiones tonales, pausas, curvas melódicas, articulaciones respiratorias, gestos, ademanes, movimientos corporales, desplazamientos, y todo tipo de reacciones psicosomáticas: suspiros, jadeos, convulsiones, llantos, temblores, contracciones musculares, etc.), muchos de ellos necesarios para completar el sentido de las frases, y otros que, a modo de comentario, enriquecen la expresividad, no sólo de los textos, sino de la situación escénica misma. De donde se deduce que tanto los elementos lingüísticos como los paralingüísticos, en cuanto componen un juego teatral, adquieren la misma importancia, por lo que requieren la misma diligente atención por parte de los responsables de las puestas en escena:

a) en lo que atañe a la preparación psicofísica de los actores, hay métodos muy eficaces que son conocidos y aplicados por los buenos regidores; en cambio,

b) en lo que respecta a la preparación vocal, los métodos educativos y reeducativos de la voz están en manos de especialistas (médicos, fonetistas, fonoaudiólogos, maestros de canto), pero que son desconocidos o desechados deliberadamente por los mediocres directores de escena.

En consecuencia, poco o nada diremos de la preparación psicocinética puesto que escapa a nuestra competencia; sin embargo, como figuramos entre los idóneos para el control lingüístico, nos atreveremos a reflexionar sobre la preparación vocal-expresiva de los actores.

Para ello, volvamos a nuestra primera premisa y recordemos que el teatro es el primero en conjuntar la comunicación lingüística-auditiva con la comunicación visual, y deduzcamos que una de las condiciones sine qua non de un buen espectáculo teatral es que el espectador escuche, y escuche bien: con claridad, nitidez y persuasión. Incluso, doblemente persuadido: $1^{\circ}$ ) porque entiende lo que se le dice; y $2^{\circ}$ ) porque se conmueve, con placer o con pesadumbre, justamente por lo que se le dice y por cómo se lo dice. Esto significa que, por parte del actor, debe decirse o pronunciarse y, a la vez, interpretarse o entonarse adecuadamente todo lo que se le transmite al espectador. Por ello, tal vez se piense que vamos a desarrollar aquí una teoría de la pronunciación y otra sobre la entonación, pero, dada la naturaleza de este artículo y, sobremanera, la de los cursos de formación actoral, nos conformaremos con esbozar un programa mínimo de acción. 
Con respecto a la pronunciación, quizá no resulte conveniente destinar largas y tediosas sesiones al adiestramiento fonético de los distintos sonidos vocálicos y consonánticos de nuestra lengua, dada la complicada y extensa variedad regional, dialectal, con el agravante de que, en este sentido, carece de fundamento científico y práctico impartir modelos unívocos que respondan a la compleja realidad lingüística. Asimismo no debe ser del todo indiferente el director de escena a la variedad dialectal ya que su conocimiento y aplicación le ha servido frecuentemente para caracterizar mejor a los personajes. Por eso, aunque sean atendibles, debemos tomar con cautela los reclamos del prestigioso fonólogo español Tomás Navarro Tomás: "A los maestros, no sólo a los que han e enseñar en Castilla, sino a los que en regiones dialectales han de encontrarse ante hábitos de pronunciación distintos de los de la lengua nacional, ni se les prepara convenientemente para esta enseñanza, ni siquiera se les pide la corrección de sus propios dialectalismos ",; y decimos con cautela, porque los dialectalismos les son útiles a los maestros para comprender a sus alumnos, incluso para comunicarse más eficazmente con ellos $y$, en el caso de la formación actoral, para flexibilizar aún más la ductilidad de los actores a la hora de abordar, por exigencias de la obra teatral, las hablas regionales de la lengua española, obviamente.

Pues bien, a más de que el reproche de Navarro Tomás se extiende a todos aquellos que usan la voz como herramienta de trabajo (actores incluidos), pensamos que, para los cursillistas de un teatro vocacional, basta una cartilla de recomendaciones meramente funcionales, que bien pueden concentrarse en una serie de ejercicios realizados a conciencia y con objetivos definidos; ejercicios que se realizarían para lograr:

a) una correcta y eficaz respiración (inspirar por la nariz y espirar por la boca) que mantiene lozano, continuamente tonificado el sonido: profesores de educación física y maestros de canto son los que conocen mejor los métodos de respiración más útiles a la actividad que desempeñan los beneficiarios (deportistas, cantantes y, en este caso, los actores);

b) una firme apoyatura diafragmática de la masa compacta de aire que provoca la emisión de los sonidos, acción que brinda cuerpo, volumen y sonoridad a la voz: profesores de canto, los cantantes mismos y también los actores saben de la necesidad de tal apoyatura, sobremanera cuando deben afrontar largas cláusulas (habladas o cantadas) en determinados tramos de las obras que interpretan. Saben que esta acción bien ejercitada les hará evitar cortes jadeantes del aliento, los que, tras ser inoportunos y desagradables, ponen en riesgo la calidad interpretativa;

c) una adecuada impostación de la voz de acuerdo con las exigencias acústicas de la sala y el público; algo semejante a lo que, en la enseñanza del canto, equivale a la colocación de

${ }^{8}$ Vid, T. NAVARRO TOMÁS, Manual de pronunciación española, Madrid, Revista de Filología Española, 1961, p. 10 . 
la voz en su tesitura natural, pero acondicionada no sólo al carácter de las escenas sino también a su auditorio;

d) una apropiada modulación y articulación de sonidos, palabras, grupos fónicos y oraciones de la obra, lo que posibilita una dicción nítida y agradable;

e) una cuidada proporción o equilibrio de las cualidades físicas del sonido: tono, timbre, cantidad e intensidad; cualidades que, combinadas de modo especial, conforman el acento, "canto o "tonada" propios de un idioma, de cualquiera de sus dialectos e idiolectos. Todo esto conduce, indudablemente, a una mejor caracterización de personajes y situaciones;

f) una segura y confiable perceptibilidad de los sonidos y de las palabras, atendiendo sobre todo a que los mismos son, según su naturaleza, unos más perceptibles que otros. De esta manera se tratará de preservar el grado de percepción necesario para una correcta audición por parte del espectador. Pero, este punto requiere un más aclaratorio desarrollo.

Es cierto, los fonemas consonánticos sordos $/ \mathrm{p} /, / \mathrm{t} /, \mathrm{s} /, / \mathrm{k} /$ (equivalente sonoro de la c delante de a, o, u, y de la q delante de e, i) son menos perceptibles que los sonoros, sobre todo en determinadas posiciones: en sílaba trabada por otro sonido consonántico (rapto, atleta, ritmo, resto, acto) y en final de palabra (vivac, cenit, compás, crup, habitat); asimismo, ciertos sonidos consonánticos sonoros, en esas mismas posiciones, suelen ser apenas perceptibles, incluso muchos hablantes siquiera amagan pronunciarlos ("verdã" por verdad, "circustancia" por circunstancia, "chipancé" por chimpancé, "ónibus" por ómnibus), o bien los sustituyen por otros sonidos ("pueulo" por pueblo, "mueule" por mueble). Con los fonemas vocálicos ocurre algo similar: desde Platón hasta nuestros días siempre se sintió que unas vocales eran más o menos perceptibles que otras; perceptibilidad que coincidía con una clasificación tradicional: a, e, o, (fuertes), i, u (débiles). De modo que el director de escena debe tomar los recaudos para salvar estos inconvenientes de perceptibilidad que podrían llegar a malograr la representación. Si a esto se añade el valor simbólico que los especialistas, en base a múltiples experimentos realizados con hablantes comunes, les adjudican a ciertos sonidos del lenguaje, es posible que logremos una audición satisfactoria $\mathrm{y}$, en consecuencia, gratificante. Los experimentos, que pretendían demostrar cómo eran sentidas algunas vocales o consonantes, arrojaron los siguientes resultados:

- la i : pequeña, ágil, amable, aguda (filosa, según Platón), linda;

- la u: gruesa, sombría, triste, fuerte, cavernosa;

- la a: grande, gorda, grasa;

- la t y la k: duras, agresivas, malvadas;

- la l: líquida, acuosa, ligera;

- la m: dulce, tierna, maternal;

- la n: velada, tenue, difusa;

- la b (fricativa): silbante'.

${ }^{9}$ Cfr. Platón, Cratilo, en OBRAS COMPLETAS, Madrid, Aguilar, 1972, pp. 540-542; y CATHERINE KERBRAT-ORECCHIONI, La connotación, Buenos Aires, Hachette, 1983, pp. 34-43. 
Ahí tiene el director de teatro material maleable para depurar el arte declamativo, a la vez que enriquece y vuelve más dúctil la pronunciación en beneficio de una mejor caracterización de los personajes. Es cuestión de saber explotar dichos valores simbólicos en la etapa de formación de los actores.

Con respecto a la entonación pueden formularse reflexiones similares a las vertidas sobre la pronunciación; es decir, entre la posibilidad de demorarnos en una extensa y penosa descripción lingüística de los innumerables aspectos melódicos y rítmicos con que deben expresarse o matizarse un texto oral y la posibilidad de habilitar una lista de sugerencias útiles para el entrenamiento actoral, nos quedamos sin vacilar con esta última. También aquí podemos apoyarnos en una gama de ejercicios que se realizarían en sesiones (individuales y grupales) de lectura expresiva, análisis psicosocial e interpretación sólo vocal de textos teatrales; en tales circunstancias, se tendrían en cuenta las recomendaciones formuladas para la pronunciación y las próximas sobre la entonación; $y$, cuando estuviere más adelantado el adiestramiento, tales recomendaciones se sumarían a las procesadas para la dinámica psicocinética. Asimismo, para que dichas sesiones no se conviertan en cámaras ciegas o falsas, se les determinaría un destino que bien puede ser el de los espectáculos domésticos, de entrecasa digamos, o el de un espectáculo público mayor del tipo de "teatro leido", muy didáctico y ameno, pese al menosprecio de muchos que piensan que la lectura de teatro es siempre una emergencia, que falsifica la obra, le resta comunicabilidad y hace muy difícil el justo aprecio de su mérito, sin pensar que aquél vale de la misma manera que los juegos escénicos mudos y que cualquiera de las variantes a que aludiéramos más arriba. Pues, las sugerencias sobre la entonación son unas pocas que se concretarían con una práctica disciplinada e intensiva:

a) reconocer, mediante ejercicios fónico-auditivos, las tres direcciones tonales básicas: la horizontal suspensiva neutra:

$$
\overline{\text { Cui }}-\overline{\text { da }}-\overline{\text { do }}-\overline{\text { con }}-\overline{\text { lo }}-\overline{\text { que }}-\overline{\text { de }}-\overline{\text { cís, }}
$$

la oblicua ascendente o aguda; por ejemplo, cierta forma de interrogación:

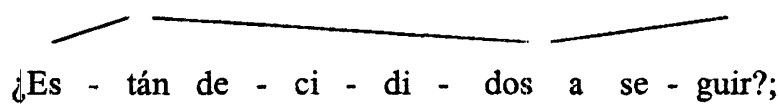

y la oblicua descendente o grave, propia de ciertas aseveraciones:

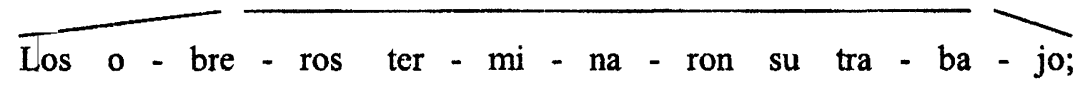


además de las variantes graduales, a la manera de una escala musical, que se verifican fundamentalmente en las dos oblicuas; incluso, las variables combinatorias abruptas que resultan más evidentes en las direcciones: grave-aguda:

$$
\text { iSa - li de a - hí!; }
$$

o agudo-grave:

$$
\text { ¡Epa! ¡Oque!; }
$$

b) asociar, en ejercicios separados, las curvas melódicas con el ritmo o movimiento (lento, acompasado o cadencioso, rápido, frenético), con las pausas (largas, semi-largas o semibreves, breves, hasta el silencio), con la cantidad o medida (alargamientos o acortamientos de sonidos, sílabas, palabras y frases), con la acentuación o intensidad emotiva de ciertas palabras dentro de los grupos fónicos de una cláusula o período, sobre todo aquéllos que cargan la mayor fuerza semántica o expresiva que el texto requiere; por ejemplo,

\section{"Eres el orgullo de Edipo" \\ "Como te imaginarás, no podia darme el lujo de tener un crápula en los dos bandos" \\ “Crees que no me asquea tanto como a ti esa carne que se pudre al sol?”}

\section{(Antígona, Jean Anouilh);}

c) asociar, en ejercicios conjuntos, las curvas melódicas con dos o más elementos esenciales en la estructura prosódica a que nos refiriéramos en el parágrafo anterior; por ejemplo, en una misma expresión, combinar la aceleración del ritmo con la elevación del volumen y, a veces, el aglutinamiento de palabras en un recurso sonoro que en música se llama "crescendo", para lograr el efecto emocional del enojo colérico o del susto. De hecho, puede ejercitarse también el recurso contrario, llamado en la técnica musical "diminuendo";

d) relacionar globalmente los perfiles tonales propios de las funciones elementales del lenguaje (expresiva, apelativa e informativa) con actos psíquicos muy humanos (emociones, voliciones, aserciones) y algunos de sus especímenes más notorios $\mathrm{y}$, de ser posible, contrastantes; por ejemplo

- de las emociones: "amor / odio", "tristeza / alegría", "sinceridad / hipocresía", "confianza / miedo", "indiferencia / curiosidad / asombro", etc.;

- de las voliciones: "lisonjas o piropos / insultos o agravios", "deseo / ruego / súplica", "exhortación / pedido / orden / mandato", "llamados de atención", "saludos de cortesía", etc.; y

- de las aserciones: aseveraciones "afirmativas / negativas", "categóricas / dubitativas", "reiterativas / elípticas", etc.; 
e) desplegar un espectro graduado de emociones y voliciones; es decir, sobre la base de un mismo sentimiento o acto de voluntad, ejercitar la gama de sutiles matices que señalan el paso de un grado a otro superior o inferior; por ejemplo

- "insinuación de deseo - deseo- pedido - ruego - exhortación - mandato - compulsión esquizofrénica"; o bien proceso inverso;

- "broma - burla — ironía - sarcasmo — cinismo", etc.; y, por supuesto, el

f) combinar todos estos mecanismos en ejercicios que destaquen los grandes cambios semánticos producidos por cambios abruptos en la entonación; esto es, sobre la base de un mismo texto, alterar las curvas melódicas para provocar deliberadamente efectos contrastantes, risueños o contrictos, ridículos o absurdos; por ejemplo,

- textos fúnebres en tono festivo, o viceversa;

- textos amorosos en tono rencoroso, o viceversa;

- textos pacíficos en tono belicoso, o viceversa;

- textos sinceros en tono hipócrita, o viceversa;

- textos irónicos en tono sarcástico o cínico, o viceversa; etc.;

g) realizar, tras el debido análisis de aproximación y conocimiento de un texto teatral, la lectura expresiva e interpretativa de algunos de sus fragmentos, teniendo en cuenta el contexto histórico-cultural y entorno espacial y psicosocial, tanto de los personajes como de las situaciones dramáticas ${ }^{10}$.

Sabemos que las sugerencias apuntadas sobre la pronunciación y la entonación de textos dramáticos no se agotan en sí mismas; que son muchas más las posibilidades de que disponen directores y actores sobre la materia; que, inclusive, las provenientes de preceptistas teatrales especializados pueden resultarles más provechosas que las nuestras. Sólo es cuestión de saberlas integrar en un proceso beneficioso y recreador por realizarse durante la preparación actoral. En este sentido, no ignoramos que la eficacia de este proceso depende del interés y conocimiento que se posea acerca del asunto que nos preocupa; del criterio-ideal de teatro como de la capacidad intelectiva y artística de regidores y preparadores; de la voluntad constante y disciplinada de los actores; $y$, obviamente, de la sensibilidad idiomática de los responsables de una representación teatral. Asimismo, seguimos confiando en los beneficios de esa integral y sistemática educación, puesto que sólo ella hará prever los riesgos perjudiciales de la

\footnotetext{
${ }^{10}$ Para los aspectos de "pronunciación" y "entonación" de la lengua española véanse de T. NAVARRO TOMÁS, aparte de la obra ya citada, Manual de entonación española, México, Colección Málaga, 1966; además, ANTONIO QUILIS y JOSEPH A. FERNÁNDEZ, Curso de fonética y fonología españolas, Madrid, S.I.C., 1971; SAMUEL GILI GAYA, Elementos de fonética general, Madrid, Gredos, 1958.
} 
improvisación, la mediocridad y la cursilería que suelen malograr un espectáculo. En suma: educación que habrá de corregir los desvíos de intuiciones y emociones descontroladas. Tal vez por eso nos cuesta entender la opinión reservada de algunos talentosos regidores y críticos teatrales: Max Libermann, por ejemplo, ha definido la diferencia entre la representación intuitiva y la calculada al hacer notar que lo importante no es que un actor ande con botas, sino que parezca andar con botas, aunque no las lleve; Diderot, quien fue uno de los mejores críticos de teatro, dijo que "para emocionar es preciso no estar emocionado"; y el maestro Sacha Guitry ha resumido a la perfección el problema al decir: "Demasiada sensibilidad, da actores mediocres; sensibilidad mediocre, da malos actores, y carencia de sensibilidad, da actores geniales" $"$. Por supuesto, estas opiniones no hacen más que ratificar la necesidad de una inteligente y bien calculada preparación actoral, en la que se involucra la preparación vocal.

Como se ve, no nos interesó meternos en honduras fónico-acústicas, ni lingüísticoestilísticas, ni técnico-teatrales; sólo quisimos reafirmar nuestra creencia de que allí donde aparece la palabra, sea por el motivo que fuere, goza ella de los mismos privilegios que los demás componentes del espectáculo teatral. Por eso, para nosotros, desconocer este principio fundamental es lo mismo que desconocer la importancia que la palabra siempre tuvo en la comunicación humana, en cualquier texto hablado o escrito, en cualquier estilo o nivel lingüístico, sea el género literario (el dramático es uno de ellos) o técnica expositiva elegidos como formas de manifestación. Si no, repásese aquella memorable página de Pablo Neruda, "La palabra", en su no menos memorable libro, Confieso que he vivido:

"... Todo lo que usted quiera, si señor, pero son las palabras las que cantan, las que suben y bajan... Me prosterno ante ellas... Las amo, las adhiero, las persigo, las muerdo, las derrito... Amo tanto las palabras... Las inesperadas... Las que glotonamente se esperan, se escuchan, hasta que de pronto caen... Vocablos amados... Brillan como piedras de colores, saltan como platinados peces, son espuma, hilo, metal, rocio... Persigo algunas palabras... Son tan hermosas que las quiero poner todas en mi poema... Las agarro al vuelo, cuando van zumbando, y las atrapo, las limpio, las pelo, me preparo frente al plato, las siento cristalinas, vibrantes, ebúrneas, vegetales, aceitosas, como frutas, como algas, como ágatas, como aceitunas... Y entonces las revuelvo, las agito, me las bebo, me las zampo, las trituro, las emperejilo, las liberto... Las dejo como estalactitas en mi poema, como pedacitos de madera bruñida, como restos de naufragio, regalos de la ola... Todo está en la palabra..."

\footnotetext{
${ }^{1 i}$ Para las opiniones de Libermann, Diderot y Sacha Guitry, cfr. A. CIRICI PELLICER op. cit., pp. 626-627.
} 